\title{
The measurement of the spatial effects of Chinese regional carbon emissions caused by exports
}

\author{
TANG Zhipeng ${ }^{1,2}$, LIU Weidong ${ }^{1,2}$, GONG Peiping ${ }^{1,2,3}$ \\ 1. Key Laboratory of Regional Sustainable Development Modelling, CAS, Beijing 100101, China; \\ 2. Institute of Geographic Sciences and Natural Resources Research, CAS, Beijing 100101, China; \\ 3. University of Chinese Academy of Sciences, Beijing 100049, China
}

\begin{abstract}
Based on the multi-regional input-output analysis, this paper improves the four traditional input-output formulas about exports resulting in multi-regional carbon emissions spatial effects which include direct effect, indirect effect, spillover effect and feedback effect. And the latter two formulas are to measure the bidirectional influences of carbon emissions induced by regional exports between two regions. The results suggest that the direct effects of Chinese eight regions induced by national exports decreased from 1997 to 2010, and the indirect effects induced by national exports also decreased except the northern coastal region and the northwestern region in China. During this period, most of Chinese coastal regions had strong spillover effects induced by their own exports. The northern coastal region and the eastern coastal region had stronger feedback effects, while the southern coastal region had weaker feedback effects and Beijing-Tianjin region had the weakest feedback effect induced by their exports. All of the inland regions had strong feedback effects, especially for Northwest and Central China, induced by their exports. More attention should be paid to the inter-regional joint efforts in order to effectively achieve Chinese national carbon-reduction target.
\end{abstract}

Keywords: export; region; carbon emissions; spatial effects; input-output

\section{Introduction}

China's economy has grown dramatically under the trade policy of earning foreign exchange through exports since reform and opening up. According to the data released by the United Nations Center of Statistics in 2014, China's exports grew by an annual average rate of $12.4 \%$ from 1981 to 2012 based on the constant price of the year 2005, which was $2.3 \%$ higher than the annual average GDP growth rate for the same period. China has developed into the global production network and established its status as the world's factory, but it has always been in the middle of the Smile Curve, and obtains small amount of profit from export commodity per unit at the expense of heavy pollution. China has become the world's first large carbon emitter shortly after it became the world's first large exporter. Under the

Received: 2015-04-10 Accepted: 2015-05-27

Foundation: National Natural Science Foundation of China, No.41201129, No.41125005

Author: Tang Zhipeng (1978-), PhD and Associate Professor, specialized in economic geography and regional sustainable development. E-mail: tangzp@igsnrr.ac.cn 
present situation of worldwide efforts to address climate change, low carbon economy becomes the only choice for China's sustainable development in the future. Economic globalization has greatly promoted the trade linkages in different regions, but it also creates some problems, among which China's carbon emissions resulting from exports have become one of the hot academic issues. China's carbon emissions accounting caused by international trade is investigated based on the national scale (Shui and Harriss, 2006; Peters et al., 2007; Weber and Mattews, 2007; Guan et al., 2008; Kahrl and Roland-Holst, 2008; Weber et al., 2008; Lin and Sun, 2010; Su and Ang, 2010; Yan and Yang, 2010; Zhang, 2012; Guo et al., 2010; Weitzel and Ma, 2014; Cui et al., 2015; Xia et al., 2015). These studies focus on embodied carbon accounting and embodied carbon transfer. In addition, one region's economic development and knowledge innovation tend to produce spillover effects on the other region (Wang et al., 2002), which means that one region's exports stimulate its own economic development and at the same time the other region's economic development; likewise, one region's exports cause not only its own carbon emissions but also the other region's carbon emissions, which, in turn, have spillover and feedback effects. Thus spillover effects and feedback effects of carbon emissions occur between two regions. However, the regional economic growth will also cause spillover effects and feedback effects in multiple regions. Direct and indirect effects of carbon emissions resulting from Chinese exports also occur in different regions. These environmental change effects are called the spatial effects of carbon emissions caused by Chinese exports. There are two main methods applied in the investigation into carbon emissions resulting from the national economy. One is the econometric analysis based on statistics. This method has a wide range of applications, but different indexes selected in an econometric model will produce different econometric analysis results and inter-regional feedback is not adequately addressed in an econometric model. The other method is the input-output analysis based on the national economy accounting, which has become a useful tool for exploring inter-regional feedback because of its systemic analysis of national economic structure as well as its relatively fixed research framework (Pan and $\mathrm{Li}$, 2007). The input-output analysis has been widely applied in the field of economy, resource and environment (Leontief, 1970) and extended to the interregional input-output analysis (Isard, 1951) and the multi-regional input-output analysis (Chenery, 1953; Moses, 1955).

Most of the above studies focus on carbon emissions accounting based on input-output analysis including carbon transfer and carbon footprint. In essence, the carbon emission accounting is the total emission calculation which includes direct carbon emission and indirect carbon emission. The indirect carbon emission is not obvious, but it is based on the direct carbon emission. Regardless of indirect carbon emission accounting or direct carbon emission accounting, they all resulted from one regional final demand. In other words, carbon transfer and carbon footprint are the ultimate effects resulting from inter-regional production. This type of influence is always extending from one region to other regions. In fact, carbon transfer and carbon footprint are a kind of final one-way effect among regions. Similarly, feedback carbon emission is based on the spillover carbon emission, and feedback carbon emission is the inter-regional bilateral effect. Under the situation of globalization this kind of inter-regional bilateral effect cannot be neglected. The carbon emissions resulting from one regional export depends on the total exports as well as the carbon emissions produced by export per unit, that is, the capability of carbon emission resulting from China's exports. This type of capability of carbon emission reflects four spatial effects of carbon emission 
including direct carbon emission, indirect carbon emission, spillover carbon emission and feedback carbon emission. The main content of the foreign trade structure optimization of China's 12th Five-Year Plan outline is to "Continue to stabilize and expand external demand, accelerate the transformation of the modes of foreign trade growth, and promote scale expansion of international trade transition to quality and efficiency". With the increasing exports, the accounting of the total carbon emissions produced by total exports is needed but the parsing of the capability of carbon emission caused by exports in different regions is more important because it provides a basis for making decisions on promoting the environmental benefits. This paper aims to pursue this line of study.

This paper measures four spatial effects of carbon emission caused by China's exports in two fields: One is to measure China's direct and indirect carbon emission increments in different regions caused by national exports; the other is to measure the inter-regional spillover and feedback carbon emission increments caused by regional exports. The four spatial effects of carbon emissions caused by China's exports are based on the multi-regional input-output analysis. In this paper the specific methods to measure spatial effects of carbon emissions caused by China's exports are introduced in the second section. The calculation results and the analysis of the four spatial effects are presented in the third section. At last we provide some policy suggestions about carbon emission reduction.

\section{Data and methodology}

\subsection{Data}

The data used in this paper are from four multi-regional input-output tables of the years of 1997, 2002, 2007 and 2010 (Zhang and Zhao, 2005; Liu et al., 2012; 2014). For lack of relevant data, the specific regions of these input-output tables only include 30 provinces of mainland China except Tibet, Hong Kong, Macau and Taiwan. The data of primary energy-related carbon emission by using IPCC method are from China energy statistical yearbook 1998, 2003, 2008 and 2011. The 30 provinces are divided into eight regions, with each region having four sectors. The eight specific regions are expressed respectively: 1 . The northeastern (NE) region including Liaoning, Jilin and Heilongjiang; 2. The Beijing-Tianjin (BT) region including Beijing and Tianjin; 3. The northern coastal (NC) region including Hebei and Shandong; 4. The eastern coastal (EC) region including Shanghai, Zhejiang and Jiangsu; 5. The southern coastal (SC) region including Fujian, Guangdong and Hainan; 6. The central (CT) region including Shanxi, Henan, Anhui, Hubei, Hunan and Jiangxi; 7. The northwestern (NW) region including Inner Mongolia, Shaanxi, Ningxia, Gansu, Qinghai and Xinjiang; 8. The southwestern (SW) region including Sichuan, Chongqing, Guangxi, Yunnan and Guizhou. And the four specific sectors are agriculture, industry, construction and services. This study focuses on China's different regional capability of carbon emissions caused by exports in the same year, therefore, all the economic data are current price of that year.

\subsection{The measurement formulas of direct and indirect effects of carbon emissions caused by national exports}

Suppose there are two regions and each region has sector n, Leontief formula can be expressed as follows: 


$$
X=(I-A)^{-1} \cdot Y=\left(I+A+A^{2}+\cdots\right) \cdot Y=L \cdot P \cdot y
$$

Here $X$ is the total output column vector caused by export, $I$ is the identity matrix, $A$ is the direct input coefficient matrix, $L$ is the Leontief inverse matrix, $Y$ is the final demand column vector, $P$ is the export structure vector and $y$ is the total export. When the direct carbon emission coefficient row vector $E$ is introduced, formula (1) can be expressed as follows:

$$
E \cdot X=E \cdot L \cdot Y=E \cdot L \cdot P \cdot y
$$

We diagonalize the related vector of formula (2), it can be expressed:

$$
\begin{gathered}
C=\hat{E} \cdot L \cdot \hat{P} \cdot y=\widehat{E} \cdot I \cdot \widehat{P} \cdot y+\widehat{E} \cdot(L-I) \cdot \hat{P} \cdot y=W \cdot y+\bar{W} \cdot y \\
W=\widehat{E} \cdot I \cdot \widehat{P}, \bar{W}=\widehat{E} \cdot(L-I) \cdot \hat{P}
\end{gathered}
$$

where $C$ is the spatial distribution matrix of carbon emission caused by export. The superscript $^{\wedge}$ means the related vectors diagonalization. $W$ is the spatial distribution matrix of direct carbon emission caused by export, it means direct effect of each regional carbon emission caused by China's exports. $\bar{W}$ is the spatial distribution matrix of indirect carbon emission caused by export, it means indirect effect of each regional carbon emission caused by China's exports. The element $w_{i j}^{t r}$ of matrix $W$ reflects an additional increment of direct carbon emission of the sector $i$ in the region $t$ induced by the sector $j$ in the region $r$ when China's exports increase one unit, similarly, the element $\bar{w}_{i j}^{t r}$ of matrix $\bar{W}$ reflects an additional increment of indirect carbon emission of the sector $i$ in the region $t$ induced by the sector $j$ in the region $r$ when China's exports increase one unit. Thus we can measure each regional direct and indirect spatial effects of carbon emissions caused by China's exports through formula (4).

\subsection{The measurement formulas of spillover and feedback effects of carbon emissions caused by regional exports}

The feedback effect of inter-regional economic growth based on input-output was not separated from spillover effect in the earlier research (Miller, 1963). In the later studies, spillover effect was separated from feedback effect of inter-regional economic growth (Round, 1985; Sonis et al., 1993; Dietzenbacher, 2002; Pan and Li, 2007). Pan's model of two regions can be expressed as follows:

$$
\left[\begin{array}{l}
X^{1} \\
X^{2}
\end{array}\right]=\left[\begin{array}{c}
L^{11} Y^{1} \\
L^{22} Y^{2}
\end{array}\right]+\left[\begin{array}{c}
S^{12} L^{22} Y^{2} \\
S^{21} L^{11} Y^{1}
\end{array}\right]+\left[\begin{array}{c}
\left(F^{11}-I\right) L^{11} Y^{1} \\
\left(F^{22}-I\right) L^{22} Y^{2}
\end{array}\right]+\left[\begin{array}{l}
\left(F^{11}-I\right) S^{12} L^{22} Y^{2} \\
\left(F^{22}-I\right) S^{21} L^{11} Y^{1}
\end{array}\right]
$$

Here $L^{11}=\left(I-A^{11}\right)^{-1}, L^{22}=\left(I-A^{22}\right)^{-1}, S^{12}=\left(I-A^{11}\right)^{-1} A^{12}, S^{21}=\left(I-A^{22}\right)^{-1} A^{21}$

$$
\begin{aligned}
& F^{11}=\left[I-\left(I-A^{11}\right)^{-1} A^{12}\left(I-A^{22}\right)^{-1} A^{21}\right]^{-1}=\left[I-S^{12} S^{21}\right]^{-1}, \\
& F^{22}=\left[I-\left(I-A^{22}\right)^{-1} A^{21}\left(I-A^{11}\right)^{-1} A^{12}\right]^{-1}=\left[I-S^{21} S^{12}\right]^{-1} .
\end{aligned}
$$

In formula (5), the first item means the intra-regional multiplier effect, the second item refers to the inter-regional spillover effect, the third item represents the inter-regional feedback effect. When we introduce summation operator of identity row vector $\alpha=\left(\begin{array}{llll}1 & 1 & \cdots & 1\end{array}\right)$, we 
can get the inter-regional specific spillover effect and feedback effect, they are expressed as formulas (6) and (7) respectively (Pan and Li, 2007):

$$
\begin{gathered}
S O^{t r}=\alpha S^{t r} L^{r r} \\
F B^{r r}=\alpha\left(F^{r r}-I\right) L^{r r}
\end{gathered}
$$

where $S O^{t r}$ is the row vector of inter-regional specific spillover effect of economic growth, the element $S O_{j}^{t r}$ means the increment of total output of region $t$ when the sector $j$ of region $r$ increases an additional unit of final demand, while $F B^{r r}$ means the row vector of interregional specific feedback effect of economic growth, the element $F B_{j}^{r r}$ means the increment of total output of region $r$ when the sector $j$ of region $r$ increases an additional unit of final demand via region $t$. When the summation operator of identity column vector $\theta$ is introduced, formula (5) can be transformed as follows:

$$
\left[\begin{array}{l}
X^{1} \\
X^{2}
\end{array}\right]=\left[\begin{array}{c}
L^{11} \widehat{P}^{1} y^{1} \theta \\
L^{22} \widehat{P}^{2} y^{2} \theta
\end{array}\right]+\left[\begin{array}{c}
S^{12} L^{22} \widehat{P}^{2} y^{2} \theta \\
S^{21} L^{11} \widehat{P}^{1} y^{1} \theta
\end{array}\right]+\left[\begin{array}{c}
\left(F^{11}-I\right) L^{11} \widehat{P}^{1} y^{1} \theta \\
\left(F^{22}-I\right) L^{22} \widehat{P}^{2} y^{2} \theta
\end{array}\right]+\left[\begin{array}{l}
\left(F^{11}-I\right) S^{12} L^{22} \widehat{P}^{2} y^{2} \theta \\
\left(F^{22}-I\right) S^{21} L^{11} \hat{P}^{1} y^{1} \theta
\end{array}\right]
$$

And furthermore, we introduce direct carbon emission coefficient diagonal matrix $\widehat{E}=$ $\operatorname{diag}\left\{E^{1}, E^{2}\right\}$, and take it as the left multiplication of formula (8), and then we can get the second item and the third item of the right of formula (8), expressed as follows:

$$
\left[\begin{array}{cc}
E^{1} & 0 \\
0 & E^{2}
\end{array}\right] \cdot\left[\begin{array}{c}
S^{12} L^{22} \hat{P}^{2} y^{2} \theta \\
S^{21} L^{11} \hat{P}^{1} y^{1} \theta
\end{array}\right]=\left[\begin{array}{c}
E^{1} S^{12} L^{22} \hat{P}^{2} y^{2} \theta \\
E^{2} S^{21} L^{11} \hat{P}^{1} y^{1} \theta
\end{array}\right]
$$

$$
\text { And }\left[\begin{array}{cc}
E^{1} & 0 \\
0 & E^{2}
\end{array}\right] \cdot\left[\begin{array}{c}
\left(F^{11}-I\right) L^{11} \widehat{P}^{1} y^{1} \theta \\
\left(F^{22}-I\right) L^{22} \widehat{P}^{2} y^{2} \theta
\end{array}\right]=\left[\begin{array}{c}
E^{1}\left(F^{11}-I\right) L^{11} \widehat{P}^{1} y^{1} \theta \\
E^{2}\left(F^{22}-I\right) L^{22} \widehat{P}^{2} y^{2} \theta
\end{array}\right]
$$

Similar to formulas (6) and (7), with the introduction of summation operator of identity row vector $\alpha$, the spillover effect and feedback effect of inter-regional carbon emission can be expressed as formulas (9) and (10):

$$
\begin{gathered}
C S O^{t r}=\alpha E^{t} S^{t r} L^{r r} \widehat{P}^{r} \\
C F B^{r r}=\alpha E^{r}\left(F^{r r}-I\right) L^{r r} \widehat{P}^{r}
\end{gathered}
$$

where $C S O^{t r}$ means the row vector of inter-regional specific spillover effect of carbon emission, the element $C S O_{j}^{t r}$ means the increment of carbon emission of region $t$ when the sector $j$ of region $r$ increases an additional unit of export. $C F B^{r r}$ means the row vector of interregional specific feedback effect of carbon emission, the element $C F B_{j}^{r r}$ means the increment of carbon emission of region $r$ when the sector $j$ of region $r$ increases an additional unit of export via region $t$. Thus, one regional spillover and feedback spatial effects of carbon emissions caused by the other regional exports can be measured by formulas (9) and (10).

\section{Results}

\subsection{The spatial distribution of direct and indirect carbon emissions caused by exports}

According to China statistical yearbooks, the eastern coastal region including Shanghai, 
Zhejiang and Jiangsu accounted for $21.5 \%, 30.7 \%, 39.1 \%$ and $40.0 \%$ of the total exports of China respectively in 1997, 2002, 2007 and 2010, and the southern coastal region including Fujian, Guangdong and Hainan occupies 46.9\%, 42.0\%, 34.5\% and 33.4\% of the total exports of China respectively. In contrast, each share of the other six regions in China's total exports was lower than 9\% (Figure 1).
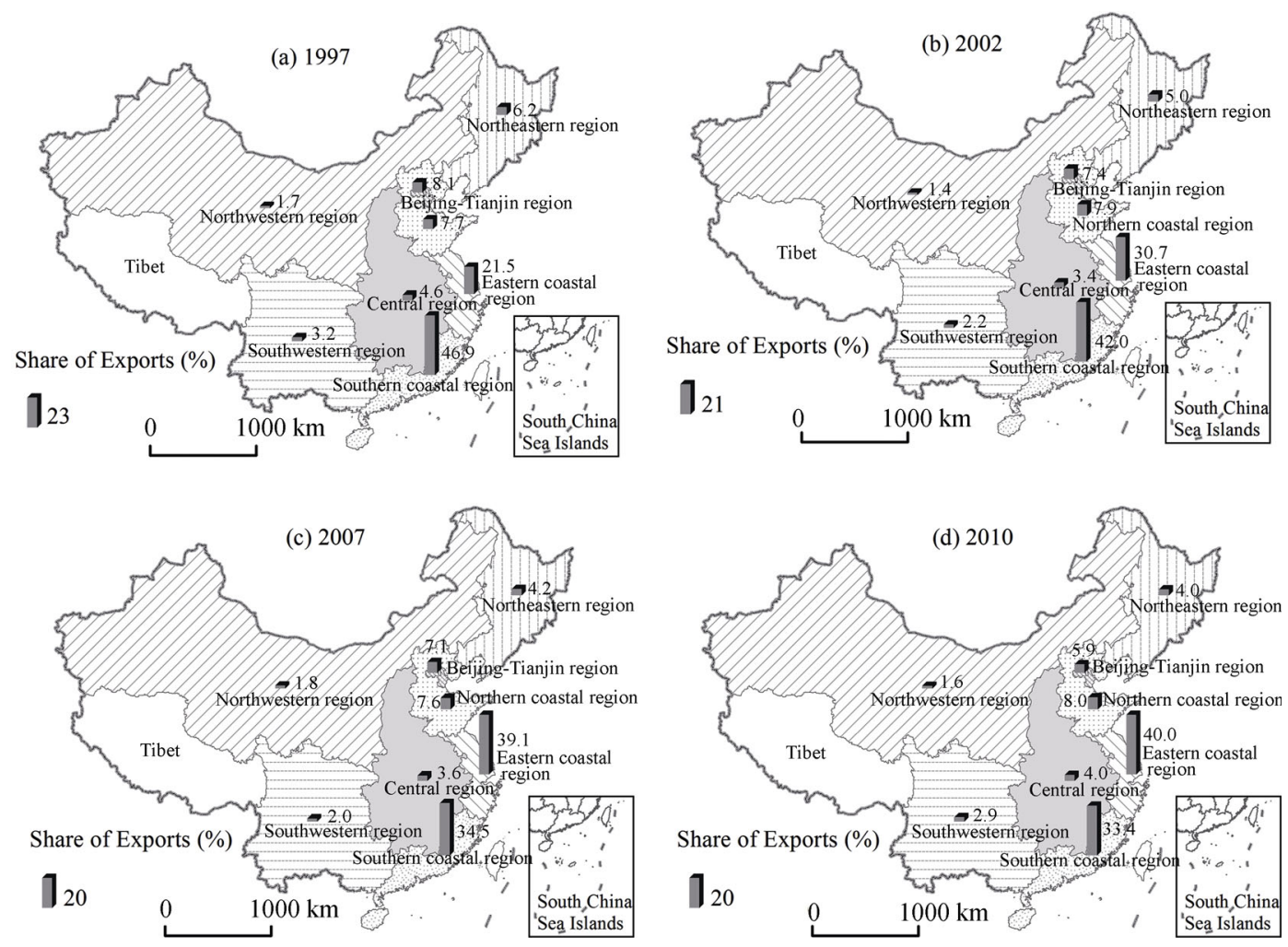

Figure 1 The share of Chinese eight regional exports during 1997-2010

Keeping the export structure of the relevant years unchanged, this paper takes 0.1 billion yuan as a unit. Increments of direct and indirect carbon emissions for each of the eight regions calculated through formula (4) are shown in Table 1 when China's exports increase 0.1 billion yuan for 1997, 2002, 2007 and 2010, respectively. Take the year 1997 as an example, when the national exports increase 0.1 billion yuan, the total carbon emissions of the northeastern region will increase 1671 tons, among which the direct carbon emissions induced by the region itself are 551 tons and the indirect carbon emissions induced itself 713 tons, the indirect carbon emissions induced by the eastern coastal region and the southern coastal region are 148 tons and 137 tons, respectively. The results for 2002, 2007 and 2010 shown in Table 1 can be explained in the same way.

As shown in Table 1, the eastern coastal region and the southern coastal region rank top in both direct and indirect carbon emissions induced by the national exports, which are closely related to their dominant positions in China's total exports. However, during the period from 1997 to 2010, the direct and indirect carbon emissions of these two regions caused by an increment of 0.1 billion yuan of national exports have declined, showing that their trade quality have been improved during this period. For example, the increment of total carbon 
Table 1 The eight regional spatial effects of the direct and indirect increase carbon emissions induced by an additional $10^{8} \mathrm{CNY}$ exports in China from 1997-2010 (ton)

\begin{tabular}{|c|c|c|c|c|c|c|c|c|c|c|c|c|}
\hline \multirow{2}{*}{ Year } & \multirow{2}{*}{ Region } & \multirow{2}{*}{$\begin{array}{l}\begin{array}{l}\text { Direct } \\
\text { emis- } \\
\text { sions }\end{array} \\
\end{array}$} & \multicolumn{8}{|c|}{ Indirect emissions } & \multirow{2}{*}{ Total } & \multirow{2}{*}{$\begin{array}{c}\text { Ratio of } \\
\text { direct emis- } \\
\text { sions (\%) }\end{array}$} \\
\hline & & & NE & BT & $\mathrm{NC}$ & $\mathrm{EC}$ & $\mathrm{SC}$ & $\mathrm{CT}$ & NW & SW & & \\
\hline \multirow{8}{*}{1997} & $\mathrm{NE}$ & 551 & 713 & 35 & 60 & 148 & 137 & 13 & 9 & 5 & 1671 & 33.0 \\
\hline & BT & 294 & 10 & 342 & 15 & 46 & 64 & 5 & 4 & 2 & 782 & 37.6 \\
\hline & $\mathrm{NC}$ & 440 & 55 & 96 & 511 & 367 & 352 & 41 & 16 & 12 & 1890 & 23.3 \\
\hline & $\mathrm{EC}$ & 810 & 23 & 18 & 34 & 1084 & 327 & 21 & 7 & 8 & 2332 & 34.7 \\
\hline & $\mathrm{SC}$ & 974 & 8 & 7 & 9 & 92 & 1014 & 8 & 3 & 6 & 2121 & 45.9 \\
\hline & $\mathrm{CT}$ & 376 & 60 & 83 & 89 & 660 & 854 & 397 & 29 & 29 & 2577 & 14.6 \\
\hline & NW & 257 & 23 & 38 & 28 & 128 & 155 & 29 & 160 & 11 & 829 & 31.0 \\
\hline & SW & 166 & 8 & 8 & 9 & 78 & 229 & 11 & 7 & 137 & 653 & 25.4 \\
\hline \multirow{8}{*}{2002} & NE & 381 & 313 & 52 & 38 & 29 & 46 & 5 & 5 & 4 & 873 & 43.6 \\
\hline & BT & 207 & 3 & 107 & 12 & 6 & 16 & 1 & 1 & 0 & 353 & 58.6 \\
\hline & $\mathrm{NC}$ & 406 & 8 & 67 & 289 & 35 & 34 & 6 & 4 & 2 & 851 & 47.7 \\
\hline & $\mathrm{EC}$ & 761 & 4 & 13 & 17 & 715 & 71 & 12 & 3 & 2 & 1598 & 47.6 \\
\hline & $\mathrm{SC}$ & 755 & 3 & 8 & 7 & 27 & 359 & 4 & 2 & 3 & 1168 & 64.6 \\
\hline & CT & 261 & 12 & 45 & 69 & 165 & 152 & 178 & 9 & 6 & 897 & 29.1 \\
\hline & NW & 170 & 14 & 23 & 24 & 68 & 50 & 9 & 91 & 5 & 454 & 37.4 \\
\hline & SW & 129 & 7 & 11 & 11 & 30 & 84 & 4 & 7 & 94 & 377 & 34.2 \\
\hline \multirow{8}{*}{2007} & $\mathrm{NE}$ & 207 & 190 & 23 & 30 & 67 & 51 & 8 & 4 & 3 & 581 & 35.6 \\
\hline & BT & 85 & 3 & 49 & 4 & 17 & 9 & 1 & 1 & 1 & 169 & 50.3 \\
\hline & $\mathrm{NC}$ & 233 & 15 & 27 & 289 & 136 & 58 & 10 & 6 & 4 & 776 & 30.0 \\
\hline & $\mathrm{EC}$ & 538 & 5 & 9 & 10 & 452 & 60 & 6 & 3 & 2 & 1086 & 49.5 \\
\hline & $\mathrm{SC}$ & 408 & 1 & 3 & 3 & 30 & 252 & 3 & 1 & 3 & 703 & 58.0 \\
\hline & $\mathrm{CT}$ & 198 & 10 & 23 & 43 & 213 & 153 & 160 & 7 & 6 & 813 & 24.4 \\
\hline & NW & 113 & 18 & 33 & 31 & 173 & 89 & 13 & 82 & 7 & 558 & 20.3 \\
\hline & SW & 83 & 2 & 7 & 7 & 41 & 112 & 5 & 2 & 63 & 320 & 25.9 \\
\hline \multirow{8}{*}{2010} & $\mathrm{NE}$ & 145 & 148 & 12 & 17 & 43 & 31 & 7 & 2 & 2 & 407 & 35.7 \\
\hline & BT & 48 & 2 & 40 & 2 & 15 & 6 & 1 & 1 & 1 & 115 & 41.8 \\
\hline & $\mathrm{NC}$ & 213 & 12 & 16 & 293 & 98 & 34 & 10 & 4 & 3 & 681 & 31.3 \\
\hline & $\mathrm{EC}$ & 428 & 4 & 7 & 8 & 414 & 43 & 6 & 2 & 2 & 914 & 46.8 \\
\hline & $\mathrm{SC}$ & 336 & 1 & 3 & 3 & 29 & 285 & 4 & 1 & 3 & 664 & 50.5 \\
\hline & $\mathrm{CT}$ & 167 & 7 & 13 & 31 & 154 & 121 & 173 & 4 & 5 & 675 & 24.7 \\
\hline & NW & 96 & 17 & 27 & 28 & 179 & 81 & 17 & 82 & 7 & 534 & 18.0 \\
\hline & SW & 79 & 2 & 5 & 7 & 35 & 85 & 6 & 1 & 77 & 297 & 26.7 \\
\hline
\end{tabular}

Note: carbon emissions here mean the sum of the increments of all the regions of all industries caused by an increment of 0.1 billion yuan of China's exports. The indirect carbon emissions caused by exports within the region means the carbon emissions of other sectors caused by the export sector in the region.

emissions in the eastern coastal region caused by an increment of 0.1 billion yuan in national exports is 2332 tons in 1997 (including 810 tons of direct carbon emissions and 1084 tons of indirect carbon emissions induced by the region itself, as well as 438 tons of indirect carbon emissions induced by other regions). And the value of the eastern coastal region for 2002 is 
1598 tons (including 761 tons of direct carbon emissions and 715 tons of indirect carbon emissions induced by the region itself, as well as 122 tons of indirect carbon emissions induced by other regions), dropping down to 1086 tons for 2007 (including 538 tons of direct carbon emissions and 452 tons of indirect carbon emissions induced by the region itself, as well as 96 tons of indirect carbon emissions induced by other regions). By 2010, the increment of total carbon emissions of the eastern coastal region caused by an increment of 0.1 billion yuan of national exports is only 914 tons including 428 tons of direct carbon emissions and 414 tons of indirect carbon emissions induced by the region itself, as well as 72 tons of indirect carbon emissions induced by other regions.

The change for the southern coastal region during this period is similar. Besides, the share of direct carbon emissions induced by the southern coastal region itself in its increment of total carbon emissions caused by the increase of national exports ranks the highest. In other words, the southern coastal region has the lowest share of indirect carbon emissions induced by the other regions in total carbon emissions induced by national exports, implying that this region has a relatively weaker economic relation with the other regions because of its engagement in processing export trade. Overall, in terms of the share of the direct carbon emissions induced by the regions themselves in their increments of total carbon emissions caused by national exports, the northern coastal region, the eastern coastal region and the southern coastal region rank top among the eight regions. As these three regions are the major exporters in China, decreasing their direct carbon emissions will play a significant role in promoting the environmental benefits of China's foreign trade. What is more, although it has low volume of exports, the central region's indirect carbon emissions induced by other regions cannot be ignored since it is the main region of energy output in China. It is also found that while for most regions the direct and indirect effects of carbon emissions induced by national exports have both decreased from 1997 to 2010, the northern coastal region and the northwestern region experienced an increase in the indirect effects of carbon emissions from 2002 to 2010. Specifically, for the northern coastal region the share of the carbon emissions induced by itself in its total indirect carbon emissions reached $62.6 \%$ in 2010 , while the share for the northwestern region is only $18.7 \%$, making it the only region with an increasing indirect effect of carbons emissions induced by other regions. Put it another way, the northwestern region has become the major source of carbon emissions induced by national exports, with Inner Mongolia, Shaanxi and Xinjiang being the main coal-producing regions in China.

\subsection{The spatial distribution of spillover and feedback effects of carbon emissions caused by regional export}

This section will parse the mutual effects of inter-regional carbon emissions on the regional level, namely the spillover and feedback effects of carbon emissions induced by regional exports. Since the eastern coastal region and the southern coastal region play dominant roles in China's exports, the spillover and feedback effects of carbon emissions induced by their respective exports from 1997 to 2010 are obtained by formulas (9) and (10), shown in Figures 2 and 3 .

As to the spillover effects shown in Figures 2 and 3, when the eastern coastal region increases its exports by 0.1 billion yuan in 1997, agriculture in other regions would increase its 

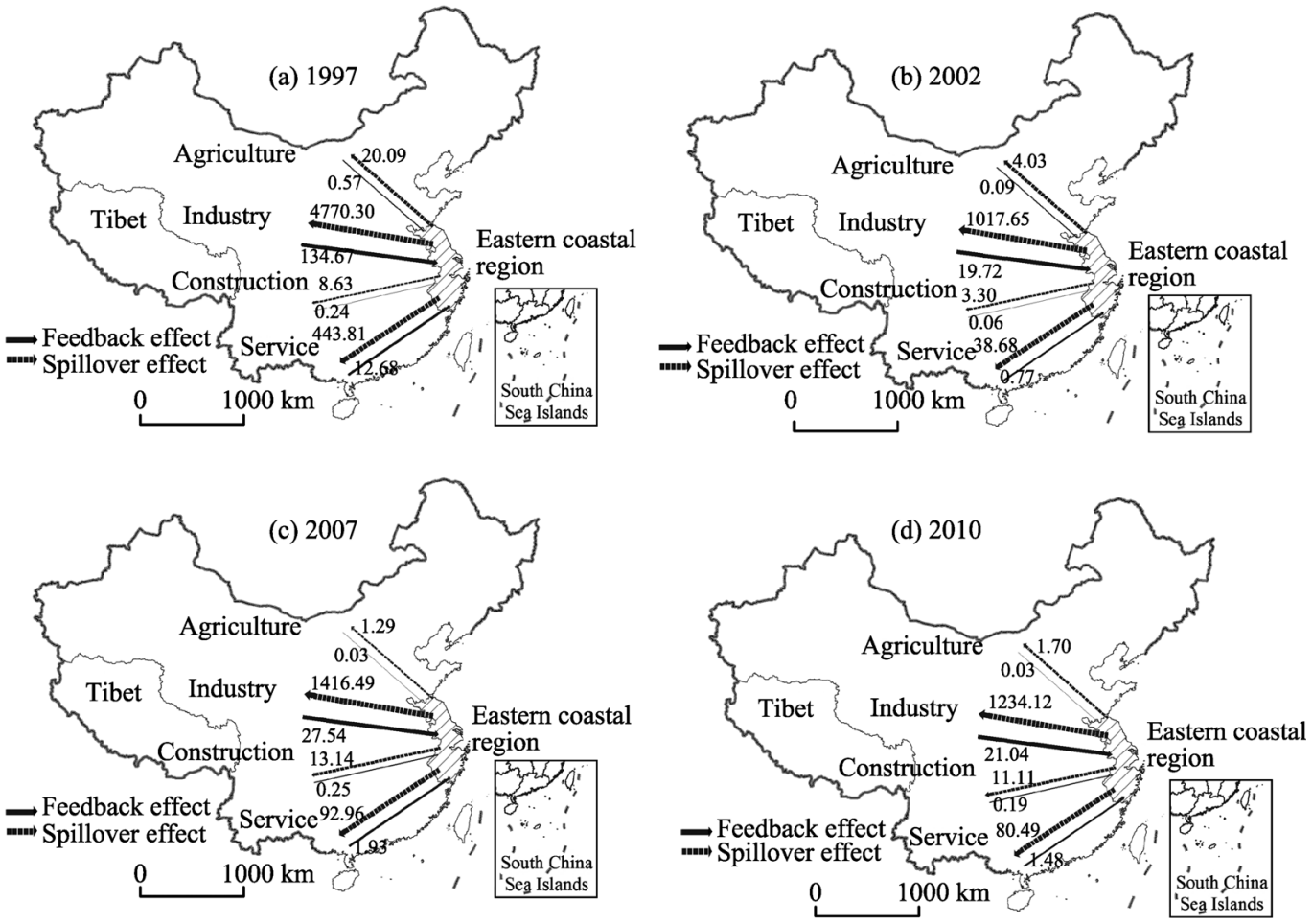

Figure 2 The amounts of spillover and feedback carbon emissions induced by an additional $10^{8} \mathrm{CNY}$ exports in Chinese eastern coastal region from 1997-2010 (ton)
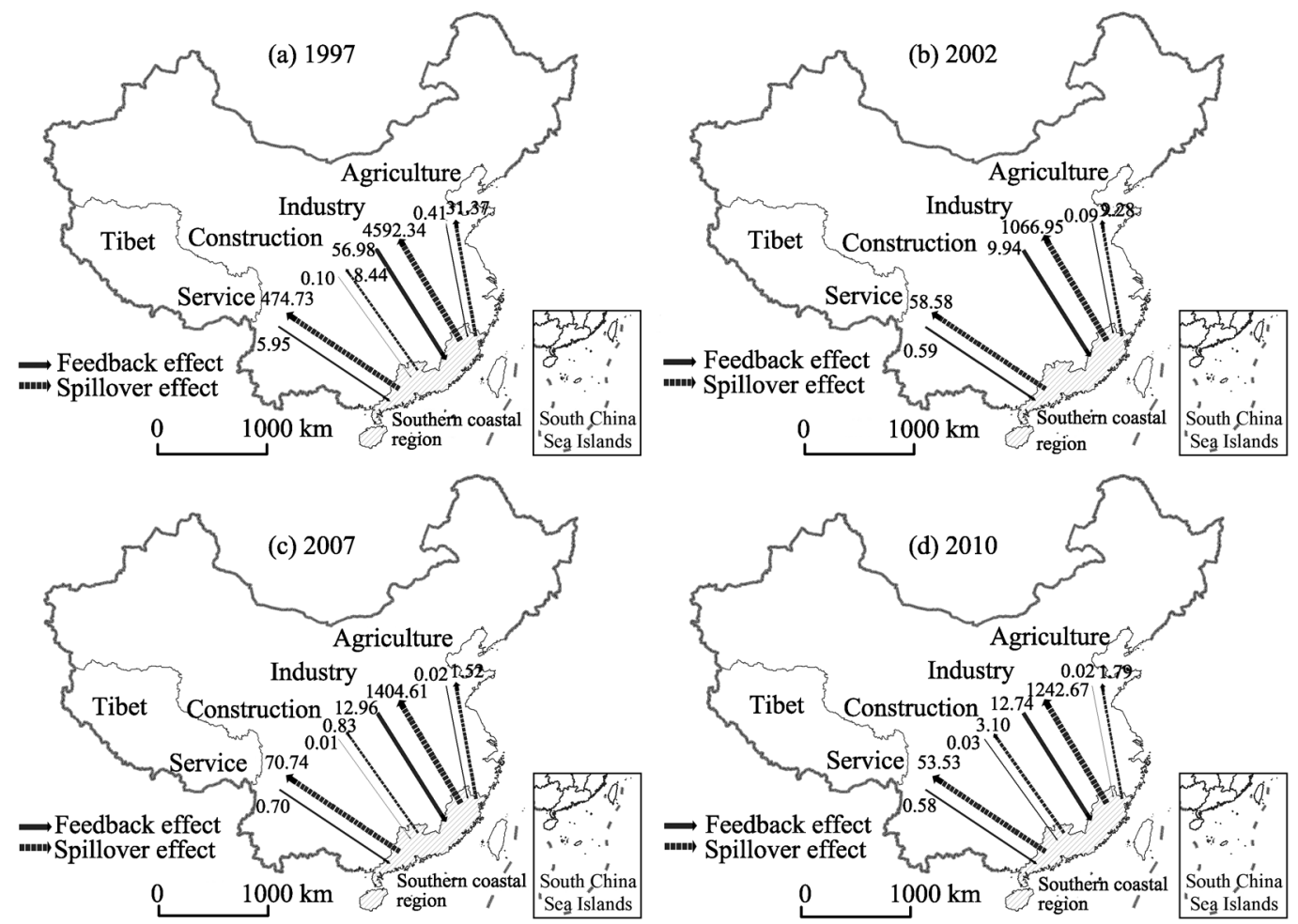

Figure 3 The amounts of spillover and feedback carbon emissions induced by an additional $10^{8} \mathrm{CNY}$ exports in Chinese southern coastal region from 1997-2010 (ton) 
carbon emissions by 20.09 tons, industry 4770.30 tons, construction 8.63 tons and services 443.81 tons. For the same scenario in 2002, agriculture, industry, construction and services would increase its carbon emissions by 4.03 tons, 1017.65 tons, 3.30 tons, and 38.68 tons, respectively. In 2007, the increments of carbon emissions in agriculture, industry, construction and services in the other regions under the same circumstance would be 1.29 tons, 1416.49 tons, 13.14 tons, and 92.96 tons, respectively. And in 2010, the figures would be 1.70 tons, 1234.12 tons, 11.11 tons, and 80.49 tons, respectively. Overall, from the results of 1997 and 2010, the carbon emissions that spill over to other regions in different sectors induced by an increment of 0.1 billion yuan in the eastern coastal region's exports, have displayed the decrease tendency. However, the carbon emissions that spilled over to the other regions in all the sectors except agriculture rebounded from 2002 to 2010.

Likewise, as the southern coastal region increases its exports by 0.1 billion yuan, carbon emissions in agriculture, industry, construction and services of other regions would rise by 31.37 tons, 4592.34 tons, 8.44 tons, and 474.73 tons, respectively in 1997. In 2002, carbon emissions in the four sectors of other regions would grow by 9.28 tons, 1066.95 tons, 0 tons and 58.58 tons. As for 2007 and 2010, the increments of carbon emissions in the four sectors of other regions induced by an increment of 0.1 billion yuan in the exports of the southern coastal region would be 1.52 tons, 1404.61 tons, 0.83 tons and 70.74 tons for the former, and 1.79 tons, 1242.67 tons, 3.10 tons and 53.53 tons for the latter. On the whole, the carbon emissions that spill over to other regions in different sectors, induced by 0.1 billion yuan's increment in the southern coastal region's exports, have been on the decline from 1997 to 2010 , similar to those of the eastern coastal region. However, while the carbon emissions spill over to other regions induced by the southern coastal region's exports have decreased in both agriculture and services from 2002 to 2010, opposite results are shown in industry and construction. Besides, between the eastern coastal region and the southern coastal region, little differences can be observed for the same sector in the spillover effect of carbon emissions induced by an increment of 0.1 billion yuan in these two regions' exports.

The investigation is also made into the carbon emissions resulting from inter-regional feedback effects, namely the part induced by increments of other regions' outputs when the region itself increases its exports by 0.1 billion yuan. Carbon emissions of the eastern coastal region as a result of feedback effects are 0.57 tons in agriculture, 134.67 tons in industry, 0.24 tons in construction, and 12.68 tons in services in 1997, respectively. And for 2002, 2007 and 2010, carbon emissions of the eastern coastal region in agriculture, industry, construction and services are 0.09 tons, 19.72 tons, 0.06 tons, 0.77 tons; 0.03 tons, 27.54 tons, 0.25 tons, 1.93 tons; 0.03 tons, 21.04 tons, 0.19 tons, 1.48 tons, respectively. Results calculated for feedback effects are the same to those for spillover effects. Carbon emissions in the eastern coastal region originated from feedback effects in different regions have decreased from 1997 to 2010 . However, for the eastern coastal region, the feedback effects of carbon emissions in all industries except agriculture have strengthened from 2002 to 2010.

As for the southern coastal region, carbon emissions induced by feedback effects are 0.41 tons in agriculture, 56.98 tons in industry, 0.10 tons in construction and 5.95 tons in services, respectively. For 2002, 2007 and 2010, carbon emissions as a result of feedback effects in the southern coastal region in the four sectors are 0.09 tons, 9.94 tons, 0 tons and 0.59 tons; 0.02 tons, 12.96 tons, 0.01 tons and 0.7 tons; 0.02 tons, 2.74 tons, 0.03 tons and 0.58 tons, 
respectively. As shown in the calculated results, carbon emissions in the southern coastal region as a result of feedback effects in all sectors had declined from 1997 to 2010 while an increasing trend could be seen in industry and construction from 2002 to 2010. On the whole, regarding to the spillover and feedback effects of carbon emissions induced by regional exports from 1997 to 2010, industry had been of great significance both in the eastern coastal region and the southern coastal region, while in agriculture and construction, they are of little influence. Furthermore, the inter-regional linkages are analyzed by calculating the ratio of carbon emissions induced by spillover effects and feedback effects for every region and the results are shown in Table 2.

Table 2 The spillover to feedback ratios of carbon emission effects induced by Chinese eight regional exports from 1997 to 2010

\begin{tabular}{clcccccccc}
\hline Year & Sector & NE & BT & NC & EC & SC & CT & NW & SW \\
\hline \multirow{2}{*}{1997} & Agriculture & 33.0 & 101.6 & 14.8 & 34.9 & 77.3 & 8.1 & 32.7 & 57.6 \\
& Industry & 33.4 & 110.0 & 15.3 & 35.4 & 80.6 & 8.1 & 32.7 & 58.1 \\
& Construction & 33.3 & 110.6 & 15.4 & 35.5 & 81.2 & 8.1 & 32.7 & 58.3 \\
& Services & 33.2 & 109.9 & 15.4 & 35.0 & 79.7 & 8.1 & 32.4 & 58.0 \\
\hline \multirow{2}{*}{2002} & Agriculture & 34.9 & 184.4 & 47.6 & 46.1 & 100.6 & 15.6 & 36.8 & 55.1 \\
& Industry & 37.7 & 194.3 & 48.0 & 51.6 & 107.3 & 15.7 & 37.7 & 55.3 \\
& Construction & 37.9 & 196.5 & 48.1 & 51.4 & - & - & 37.9 & 56.0 \\
& Services & 36.5 & 185.8 & 43.3 & 50.4 & 99.7 & 15.5 & 37.3 & 52.5 \\
\hline \multirow{2}{*}{2007} & Agriculture & 28.5 & 129.2 & 20.0 & 48.8 & 98.9 & 11.4 & 15.4 & 39.3 \\
& Industry & 29.7 & 153.6 & 21.2 & 51.4 & 108.3 & 11.9 & 15.6 & 40.8 \\
& Construction & 29.9 & 163.5 & 21.2 & 51.9 & 106.2 & - & 15.8 & 41.2 \\
& Services & 28.6 & 148.4 & 20.5 & 48.2 & 101.8 & 11.7 & 15.0 & 40.1 \\
\hline \multirow{2}{*}{2010} & Agriculture & 41.5 & 164.3 & 24.9 & 56.5 & 91.5 & 14.2 & 13.4 & 41.7 \\
& Industry & 42.8 & 187.3 & 26.3 & 58.7 & 97.5 & 14.7 & 13.5 & 43.0 \\
& Construction & 42.8 & 194.2 & 26.3 & 59.0 & 95.6 & 14.7 & 13.6 & 43.1 \\
& Services & 41.0 & 180.6 & 25.2 & 54.3 & 92.1 & 14.5 & 13.0 & 42.0 \\
\hline
\end{tabular}

Specifically, comparisons of the ratio of carbon emissions induced by spillover effects and feedback effects of industry are made in the eastern coastal region and the southern coastal region. As Table 2 shows, the ratios of the eastern coastal region in 1997, 2002, 2007 and 2010 are $35.4,51.6,51.4$, and 58.7, respectively, and the ratios of the southern coastal regions in the four years are 80.6, 107.3, 108.3, and 97.5, respectively. Although the carbon emissions induced by 0.1 billion yuan's increment in national exports from 1997 to 2010 are nearly the same in these two regions, the carbon emissions induced by feedback effects for the eastern coastal region are much higher than those in the southern coastal region, indicating that the eastern coastal region had a much closer relationship with the rest of the regions in energy (carbon emissions) connections than the southern coastal region did. The coastal region's economic growth has a great dependence on the market outside. Particularly, the eastern coastal region has a large economy of manufacturing and processing industries so that it demands plenty of intermediate inputs. So the eastern coastal region has a much stronger connections with the domestic economy and the carbon emissions induced by the 
eastern coastal region, both within and outside the region, are high. In contrast, the southern coastal region has a high percentage of processing trade and relies more on the international market, leading to relatively weaker inter-regional effects on the domestic economy. Relevant research on the impact of exports based on the inter-regional economic linkages also demonstrates that the southern coastal region has a high dependence on the processing trade because of its substantial participation in the international market rather than in the domestic market. By comparison, the eastern coastal region relies much on both the international and the domestic market (Shi et al., 2006). Different from these two regions, the northeastern region, the northern coastal region, the central region, the northwestern region and the southwestern region are more closely linked to the domestic market outside their own regions.

Shown in Table 2, the ratio of carbon emissions induced by spillover effects and feedback effects of the four sectors for the above five regions are much lower from 1997 to 2010 . These five regions have strong feedback effects of carbon emissions as they were the main providers of high energy-consuming products for the other regions and thus rely much on the other regions' development. Besides, the Beijing-Tianjin region remained the highest ratios as this region had strong spillover effects of carbon emissions but weak feedback effects on the other regions from 1997 to 2010. Though being one of the fastest-growing regions in Bohai Rim, the Beijing-Tianjin region doesn't develop effective mechanism for sharing its economic resources with other regions due to its special administrative function orientation. And this region consumes lots of energy- and resource-consuming products from other regions, causing lots of carbon emissions to spill over to the other regions. This finding provides further evidence for the view that unlike the other regions, the Beijing-Tianjin region has not developed efficient radiation power to stimulate the development of the other regions yet.

\section{Conclusions}

Exports have been a primary driving force for Chinese economic growth. The carbon emission resulting from one regional export depends not only on total exports, but also on carbon emissions per unit of export, that is, the capability of carbon emissions resulting from China's exports. Research on the spatial distribution of capability of carbon emissions resulting from China's different regional exports is of great significance for effectively achieving Chinese national carbon-reduction target in order to transform the mode of foreign trade growth. This paper improves four traditional input-output formulas of exports resulting in multi-regional carbon emissions spatial effects to parse the capabilities of carbon emissions caused by China's exports for different regions. The former two formulas carefully distinguish among the provincial sources of direct and indirect carbon emissions, providing a more scientific approach to delaminating responsibility for emissions and carrying out ecological compensation. The latter two formulas apply the concepts of spillover and feedback effects from inter-regional economic development to the analysis of problems concerning resources and environment. Main conclusions obtained in this empirical analysis are as follows.

(1) From the point of view of one-way effect of carbon emissions induced by national 
exports, the direct effects of Chinese eight regions induced by national exports decreased from 1997 to 2007, and the indirect effects also declined in all the regions except the northern coastal region and the northwestern region from 2002 to 2010. To be specific, the eastern coastal region, the southern coastal region and the northern coastal region rank top in the direct carbon emissions induced by national exports, while in the indirect carbon emissions, the first three places were occupied by the central region, the northwestern region and the southwestern region. From the point of view of inter-regional bilateral effect of carbon emissions induced by regional exports, the eastern coastal region, the southern coastal region and the Beijing-Tianjin region had strong spillover effects induced by their exports from 1997 to 2010. As to the feedback effects, the central region and the northwestern region were the strongest, while the Beijing-Tianjin region was the weakest. Besides, industry was always the one that had the strongest spillover effects as well as the strongest feedback effects of carbon emissions for all the regions induced by their own exports.

(2) Since reform and opening-up, the implementation of the strategic thought of "two overall situations" makes the coastal regions in the downstream of the production chains of export products and the inland regions locked in the upstream. From the traditional point of view of one-way effect of carbon emissions induced by national exports, the coastal regions should pay more attention to the direct effects of carbon emissions while the inland regions should focus on the indirect effects, which are reconfirmed in this paper. Based on the inter-regional bilateral effect of carbon emissions induced by regional exports, the northern coastal region and the eastern coastal region gain considerable feedback carbon emissions while lots of carbon emissions spill over to these regions. But the southern coastal region with a high level of processing trade gains relatively less feedback carbon emissions. At the same time, as the Beijing-Tianjin region doesn't develop effective economic connections with the other regions as a result of its special administrative function orientation, this region gains little feedback carbon emissions. In contrast, since the northeastern region, the northwestern region, the central region and the southwestern region have strong bilateral economic relationships with the other regions, they have strong feedback effects of carbon emissions as well as strong spillover effects of carbon emissions. More specifically, the northwestern region and the central region, where many provinces rich in energy resources are concentrated, gain much more feedback carbon emissions than the northeastern region and the southwestern region do.

(3) Regional emission reduction policies at present are mostly top-down task decomposition from the state to provinces, cities and counties with clear vertical hierarchy. However, taking inter-regional economic connections into consideration, we should pay more attention to inter-regional joint efforts to reduce carbon emissions so as to avoid carbon leakage and contribute to effectively achieving the national carbon-reduction target. Since the capability of the carbon emissions resulting from China's different regional exports vary across different regions as shown in this paper, 'one-size-fits-all' regional emission reduction policies are unreasonable. In this case differentiated regional emission reduction policies should be adopted. That is, the reduction policies adopted should be in line with local conditions. Specifically, in the coastal regions, enhancing energy efficiency should be the focus for the northern coastal region and the eastern coastal region; "import substitution" policies can be adopted by the southern coastal region that is heavily dependent on the international market; 
for the Beijing-Tianjin region, importance should be attached to breaking up the administrative boundaries to promote its economic radiation capability and helping other regions improve energy conversion efficiency so as to decrease the carbon leakage. Meanwhile, the inland regions are encouraged to adopt industrial diversification strategy to change the simplified energy- and resource-based trade pattern with other regions. Top priority should be given to the improvement of the energy conversion efficiency in the northwestern region and the central region and then in the northeastern region and the southwestern region. This measurement is useful for inland regions to reduce carbon emissions within and outside the regions in the case of bilateral effects of carbon emissions induced by regional exports.

(4) Based on the multi-regional input-output analysis, this paper improves four traditional input-output formulas about exports resulting in multi-regional carbon emissions spatial effects which include direct effect, indirect effect, spillover effect and feedback effect. Approaches employed in this paper can be also applied to more complex elements of human-land relationship in regional sustainable development analysis, such as the spillover and feedback effects of carbon emissions caused by investment and consumption. Another application of the approaches is to parse the emissions of other environmental pollutants including sulphur dioxide and industrial wastewater induced by final demands. In addition, the formulas given in this paper can also be used to investigate regions at the Municipal and county level other than the large-scale sub-national regions. In brief, the measurements of spatial effects utilized in this paper have a wide range of applications.

\section{References}

Chenery H, 1953. Regional analysis. In Chenery H, Clark P, Pinna V (eds). The Structure and Growth of the Italian Economy. Rome: U.S. Mutual Security Agency.

Cui L B, Peng P, Zhu L, 2015. Embodied energy, export policy adjustment and China's sustainable development: A multi-regional input-output analysis. Energy, 82: 457-467.

Dietzenbacher E, 2002. Interregional multipliers: Looking backward, looking forward. Regional Studies, 36(2): 125-136.

Guan D, Hubacek K, Peters G P et al., 2008. The drivers of Chinese $\mathrm{CO}_{2}$ emissions from 1980 to 2030. Global Environmental Change, 18(4): 626-634.

Guo J, Zou L L, Wei Y M, 2010. Impact of inter-sectoral trade on national and global $\mathrm{CO}_{2}$ emissions: An empirical analysis of China and US. Energy Policy, 38(3): 1389-1397.

Isard W, 1951. Interregional and regional input-output analysis: A model of a space economy. The Review of Economics and Statistics, 33(4): 318-328.

Kahrl F, Roland-Holst D, 2008. Energy and exports in China. China Economic Review, 19(4): 649-658.

Leontief W, 1970. Environmental repercussions and the economic structure: An input-output approach. The Review of Economics and Statistics, 52(3): 262-271.

Lin B Q, Sun C W, 2010. Evaluating carbon dioxide emissions in international trade of China. Energy Policy, 38(1): 613-621.

Liu W D, Chen J, Tang Z P et al., 2012. China's 30 Provincial Multi-regional Input-output Table Theory and Practice in 2007. Beijing: China Statistics Press. (in Chinese)

Liu W D, Tang Z P, Chen J et al., 2014. China's 30 Provincial Multi-regional Input-output Table Theory and Practice in 2010. Beijing: China Statistics Press. (in Chinese)

Miller R E, 1963. Comments on the "General Equilibrium" model of Professor Moses. Metroeconomica, 15(2/3): $82-88$.

Moses L N, 1955. The stability of interregional trading patterns and input-output analysis. The American Eco- 
nomic Review, 45(5): 803-832.

Pan W Q, Li Z N, 2007. Feedback and spillover effects between coastal and non-coastal regions of China. Economic Research Journal, (5): 68-77. (in Chinese)

Peters G P, Weber C L, Guan D et al., 2007. China's growing $\mathrm{CO}_{2}$ emissions: A race between increasing consumption and efficiency gains. Environmental Science \& Technology, 41(17): 5939-5944.

Round J I, 1985. Decomposing multipliers for economic systems involving regional and world trade. Economic Journal, 95(378): 383-399.

Shi M J, Jin F J, Li Na et al., 2006. Interregional economic linkage and regional development driving forces based on an interregional input-output analysis of China. Acta Geographica Sinica, 61(6): 593-601. (in Chinese)

Shui B, Harriss R C, 2006. The role of $\mathrm{CO}_{2}$ embodiment in US-China trade. Energy Policy, 34(18): 4063-4068.

Sonis M, Oosterhaven J, Hewings G J D, 1993. Spatial economic structure and structural changes in the EC: Feedback loop analysis. Economic Systems Research, 5(2): 173-184.

$\mathrm{Su} \mathrm{B}$, Ang B, 2010. Input-output analysis of $\mathrm{CO}_{2}$ emissions embodied in trade: The effects of spatial aggregation. Ecological Economics, 70(1): 10-18.

Wang Z, Deng Y, Ge Z P et al., 2002. Theoretical Economic Geography. Beijing: Science Press. (in Chinese)

Weber C L, Matthews H S, 2007. Embodied environmental emissions in U.S. international trade: 1997-2004. Environmental Science \& Technology, 41(14): 4875-4881.

Weber C L, Peters G P, Guan D et al., 2008. The contribution of Chinese exports to climate change. Energy Policy, 36(9): 3572-3577.

Weitzel M, Ma T, 2014. Emissions embodied in Chinese exports taking into account the special export structure of China. Energy Economics, 45(c): 45-52.

Xia Y, Fan Y, Yang C H, 2015. Assessing the impact of foreign content in China's exports on the carbon outsourcing hypothesis. Applied Energy, 150: 296-307.

Yan, Y, Yang, L, 2010. China's foreign trade and climate change: A case study of $\mathrm{CO}_{2}$ emissions. Energy Policy, 38(1): 350-356.

Zhang Y X, Zhao K, 2005. Interregional Input-output Analysis. Beijing: Social Sciences Academic Press (China). (in Chinese)

Zhang Y, 2012. Scale, technique and composition effects in trade-related carbon emissions in China. Environmental \& Resource Economics, 51(3): 371-389. 